\title{
La Primera Línea de la Falange contra la República
}

\author{
José Antonio Parejo Fernández \\ Universidad de Sevilla
}

\section{The First Line of the Falange against the Second Spanish Republic}

RESUMEN

Partido de retaguardia, reunión de emboscados, así fue como al poco tiempo comenzó a ser vista la Falange por sus propios socios. Emboscados, en principio,

lo fueron aquellos individuos, malos españoles en el imaginario colectivo de la derecha reaccionaria, que pudieron luchar contra la República y no lo hicieron. En la práctica, sin embargo, dicho calificativo respondió a un sentimiento muy concreto que se extendió por buena parte de la España Nacional y que vino a identificar a aquellos malos patriotas con los falangistas de la retaguardia. Así, mientras aquellos oportunistas conspiraban a salvo de las balas para imponer su modelo de estado totalitario y excluyente, en los frentes de batalla y a decir de los reaccionarios luchaban muchos españoles con nobleza y elevación de espíritu. Las continuas concentraciones, los desfiles, las misas al aire libre, los rituales nocturnos de antorchas protagonizadas por la Falange, aquella acusación, sin duda legítima a tenor de todo esto, se apoyó, no obstante, en una percepción torcida de la realidad. Con este artículo, por tanto, $y$ acudiendo a fuentes documentales hasta ahora inéditas, pretendemos dejar en sus justos términos

\section{ABSTRACT}

Ambushed, in principle, they were it who they could fight against the Republic and they didn't make it. In the practice, however, that epithet was used by the reactionary right to attack the falangists of the rearguard. According to the reactionaries, while those opportunists conspired safe of the bullets to impose their model of totalitarian state, in the battle fronts many Spaniards fought with nobility and spirit elevation. The continuous concentrations, the parades, the religious rituals outdoors, the night rituals of brands played by the Falange, that accusation leaned on, nevertheless, in a bent perception of the reality. With this article, therefore, and using unpublished documental sources, we want to analyze the contribution of a Falange that became a fundamental pillar for the overthrow of the Second Spanish Republic in very little time.

KEYWORDS:

Spain, Andalusia, Falange, Fascism, Spanish Civil War, Society, Politics, 
la aportación de una Falange que en muy poco tiempo se convirtió en un pilar fundamental para el derrocamiento de la República.

\section{PALABRAS CLAVE:}

España, Andalucía, Falange, Fascismo, Guerra Civil Española, Sociedad, Política

Cuando a través de las memorias y documentos de archivo viajamos en el tiempo hasta la España sublevada, una de las cuestiones que inmediatamente llaman la atención es la enorme difusión que en muy poco tiempo alcanzó un apelativo como el de emboscado. En principio, emboscados lo fueron aquellos individuos, malos españoles en el imaginario colectivo de la derecha reaccionaria, que pudieron luchar contra la República y no lo hicieron. En la práctica, sin embargo, dicho calificativo respondió a un sentimiento muy concreto que se extendió por buena parte de la España Nacional y que vino a identificar a aquellos malos patriotas con los falangistas de la retaguardia. Así, mientras aquellos oportunistas conspiraban a salvo de las balas para imponer su modelo de estado totalitario y excluyente, en los frentes de batalla y a decir de los reaccionarios luchaban muchos españoles con «nobleza y elevación de espíritu»"; patriotas como, por ejemplo, Luis Miralles, amigo de Eugenio Vegas Latapie, al cual una noche durante una guardia le dijo lo siguiente: «es magnífico estar aquí luchando por Dios y por España. Yo me encontraba estudiando en Italia, pero al ver el cariz que tomaban las cosas exigí a mis hermanos que avisaran en cuanto supiesen que iba a producirse el alzamiento... Y fue precisamente nuestra madre la que les pidió, poco antes de morir, que me hicieran llegar el aviso prometido „2. Emboscados, por tanto, en aquella España alzada contra la República, lo fueron Dionisio Ridruejo; emboscados, también, todos aquéllos que se dedicaron a desfilar por las calles de las ciudades; falangistas que muy pronto se vieron ridiculizados en la siguiente tonadilla:

Cara al sol,

al sol que más calienta,

me puse el gorro antes de ayer.

Me hallará la muerte,

si me llega,

sentado en el café.

Formaré junto a mis compañeros, para hacer desfiles postineros.

1 Vegas Latapie, E.: Los caminos del desengaño. Memorias políticas II, 1936-1938, Madrid, Tebas, 1987, p. 60.

2 Ibídem. 


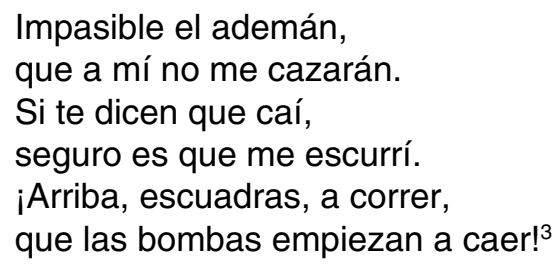

Entonada con la música del Cara al Sol, cantada en voz baja y a escondidas, raro fue el combatiente de aquella extrema derecha española que no se aprendió semejante coplilla. Ahora bien, aquel desprecio que levantaron los falangistas entre sus socios no siempre se expresó a sus espaldas.

Visto desde la óptica reaccionaria, lo que estuvo ocurriendo era muy grave: socios en la cruzada, rivales porque la Falange luchaba por imponer ese modelo de estado totalitario con el que ellos no comulgaban y, a la hora de la verdad, estafados porque en una estafa se había convertido la participación de la Falange en la contienda. Por eso, no tuvo nada de extraño que, a la primera de cambio, surgieran los conflictos entre aquellos socios mal avenidos. Disputas, por ejemplo, como las habidas en Sevilla días antes de la Unificación, cuando un jefe al frente de una Centuria falangista en marcial desfile puso el grito en el cielo al ver que, al paso por el cuartel del Requeté, nadie de los allí presentes les rendía los honores que, según él, se merecía la Falange. Tremenda descortesía, pensó, el no organizarle una guardia protocolaria a su centuria, tan insoportable que inmediatamente le dio curso reglamentario a la subsiguiente queja. $\mathrm{Y}$, claro, con unos falangistas emboscados que, en vez de irse a los frentes, se dedicaban a molestar con impertinentes protestas, la respuesta de los carlistas no se hizo esperar: Querido Federico, comenzaba la réplica,

Me dicen que esta mañana a tu paso por este Cuartel al mando de la Falange de la Segunda Línea protestaste de que no se te formara la guardia. No creo necesario decirte porque el Requeté lo tiene bien demostrado que no solo lo que manda la Ordenanza, sino también cuantas atenciones y actos de cortesía hacia la Milicia hermana podamos tener estamos en la mejor disposición de hacerlo ahora como siempre, pero a lo que no podemos llegar es a lo imposible. Y es imposible formarte la guardia por la sencilla razón de que no la había ya que no puede llamarse guardia a dos individuos y un cabo únicos que tenemos en el cuartel.

Y como veían venir lo que pasaría en el futuro, los carlistas decidieron que o les paraban los pies a los falangistas, o estaba claro que entonces no tendrían más remedio que estar todos los días expectantes a las frecuentes paradas marciales de una Falange que ya muchos empezaban a calificarla como la milicia de la Segunda Línea y los desfiles sin fin, tal y como nos lo demuestra la continuación de la réplica tradicionalista que citábamos antes:

\footnotetext{
3 Ibídem.
} 
Porque siguiendo las normas de nuestra organización tenemos a todos los hombres menores de 35 años y todos los fusiles de que podemos disponer en los frentes de combate, hasta el punto de que el último parte de revista de armamento que obra en esta Comandancia Militar dice que «el fusil y el mosquetón que existe en el cuartel están en perfecto estado de conservación». Accidentalmente suele haber en esta mayor número de hombres y fusiles correspondientes a los individuos heridos convalecientes y tan pronto se reúnen 20 dados de alta vuelven al frente [...]. Esta es la razón por la que no se te formó la guardia, debiste suponer que alguna habría cuando no se había hecho pero si alguna vez pasas por el frente de Córdoba donde nuestros hombres en unión de la Gloriosa Falange de Canarias marchan al combate y a la muerte sin que nadie LE FORME LA GUARDIA seguramente no faltará quien te la forme allí donde está el sitio del honor y donde no se comprenden esas pequeñas miserias de retaguardia. Esperando quedarás satisfecho con estas explicaciones que con el mayor gusto te doy para que no creas hubo desatención no descortesía en lo que sólo imposibilidad queda como siempre tuyo afmo. y buen amigo y compañero ${ }^{4}$.

Partido de retaguardia. Ésa fue la imagen que sus socios se hicieron de la Falange. $Y$ no fueron los únicos que así opinaron. En efecto, tan extendida estuvo aquella idea que ésta pasó a convertirse muy pronto en un lugar común, en una foto fija a la que continuamente recurrieron, en sus ataques contra los falangistas, todos los conservadores de la España sublevada. Así lo hicieron aquellos carlistas sevillanos, así lo hace cada dos por tres Eugenio Vegas Latapie en sus memorias y así, también, un vecino de Cazalla de la Sierra, pequeña población cabecera judicial de la Sierra Norte de Sevilla, el cual cansado de tanta colecta requisitoria, acusó a toda la plana local de FE de ser un partido de oportunistas que sólo buscaban en las oficinas de la Organización, en la quietud de la Segunda Línea y en los continuos desfiles el remedio eficaz que los apartase de los frentes de batalla ${ }^{5}$. Fue un pulso en toda regla, entre una Falange convertida en una organización de masas ${ }^{6}$ y una derecha tradicional y reaccionaria que muy pronto comenzó a ver en la Falange, en su estilo y en su praxis una anomalía inexplicable en la nueva España. Un pulso que creyeron ganar los falangistas y que al final, con el paso del tiempo, los llevó a la derrota definitiva; un pulso que gracias a gentes como Antonio Bahamonde, Edmundo Barbero o Jean Alloucherie ${ }^{7}$ pasó también a la España republicana.

4 Archivo Carlista de Sevilla, Sección Melchor Ferrer, Leg. 15, Oficio del 14-marzo-1937.

5 PAREJo FernándeZ, J.A.: La Falange en la Sierra Norte de Sevilla (1934-1956), Sevilla, UniversidadAteneo, 2004, p. 96.

6 La transformación en un partido de masas puede seguirse en PAREJO FERNÁNDEZ, J.A.: Las piezas perdidas de la Falange: el sur de España, (Tesis Doctoral), Universidad de Sevilla, 2005, actualmente en vías de publicación.

7 Antonio Bahamonde fue un editor de derechas, afincado en Sevilla que llegado el 18 de julio sería nombrado Delegado de Prensa y Propaganda en la Segunda División de Queipo, el cual pasado el tiempo consiguió huir, escribiendo posteriormente un magnífico aunque propagandístico libro sobre el feudo de Queipo. Edmundo Barbero, cineasta, pasó unos cuantos meses entre las provincias de Córdoba (donde le cogió rodando una película) y Sevilla, de la que finalmente consiguió salir. Como Antonio Bahamonde, al escapar también puso por escrito sus andanzas y experiencias. Ambos escritos, así como otro más de un periodista del diario L'Humanité, han sido recogidos recientemente en un libro, prologado por Alfonso Lazo, cuya cita completa es la siguiente: BAHAMONDE y SÁNCHEZ DE CASTRO, A.: Un año con Queipo de Llano. Memorias de un nacionalista (seguido de Noches de Sevilla de Jean Alloucherie y de El infierno azul de Edmundo Barbero), Sevilla, Editorial Renacimiento, Colección Espuela de Plata, 2005. 
«Lejos de los cañones y las ametralladoras, estos «bravos» falangistas se dedican a la limpieza de la retaguardia» ${ }^{8}$. Éste es el pie de foto que hay bajo la fotografía número cinco que el reportero del diario L'Humanité incluyó en su relato. En principio, una escena más de tantas que se documentaron durante aquellos años de guerra. El problema surge cuando al fijarnos en los detalles resulta que lo recogido en ese pie de foto no tiene nada que ver con lo que se puede apreciar en la imagen. El pueblo vacío, las casas de la plaza cerradas a cal y canto, nadie en los balcones, los falangistas en posición de defensa; más que limpiando la retaguardia, como decía el periodista del diario comunista francés, la impresión que uno obtiene cuando repasa la imagen con detenimiento es la de una escuadra de vanguardia realizando las operaciones de reconocimiento típicas de una unidad militar que entra por primera vez en una población aún por conquistar:

Y a la hora se entraba en Cazalla, desolada y triste como una ciudad muerta. Hasta la plaza de la iglesia ni un alma: solas las calles ${ }^{9}$. En el pueblo [Constantina] todo es soledad. Las casas, cerradas, y en todos los balcones banderas rojas o rojas y negras ${ }^{10}$.

Basta, por tanto, comparar la fotografía con estos dos relatos o con todos los que a diario fueron apareciendo en la prensa sevillana durante aquellos días, cotejarla incluso con otras imágenes que se incluyen en la propia obra de Allouchery y en la que puede verse a una columna con los fusiles al hombro paseando por las calles de un pueblo, para afirmar que en este caso, y como en tantos otros, el enviado del diario francés fue otro de los que se dejaron llevar por la extendida leyenda de unos emboscados que en esas fotos no aparecen por parte alguna. $Y$ fue así cómo, al publicarse testimonios como los que hemos visto, aquel mito pasó a la zona republicana, de tal manera que esto es lo que explica por qué la historia de los emboscados y otras más que escapan a al ámbito de este artículo iban a tener una larga vida en la memoria colectiva de los españoles y también entre buena parte de nuestra historiografía actual.

Sin duda, los sentimientos que expresaban aquellas tonadillas y aquellas arremetidas contra la Falange respondieron en gran medida a una realidad incuestionable. Los sevillanos, por ejemplo, tras el 18 de julio vieron cómo una legión de jóvenes, muchos de ellos en edad militar y otros muchos provenientes de las mejores familias de la ciudad, pasó a engrosar las filas de una Falange que en cuestión de pocos meses, mucho antes incluso de la Unificación, pasó a convertirse en la más numerosa de cuantas organizaciones se habían alzado contra la República. Una Falange cuyas banderas de Primera Línea participaron desde los

${ }^{8}$ El pie de foto que hemos citado corresponde a la imagen número 5 que se incluye en el citado apéndice fotográfico que Allouchery incluyó en su reportaje.

9 Hasta aquí el relato del periodista que acompañaba a las tropas que ocuparon Cazalla de la Sierra el 15 de agosto de 1936. La crónica en el diario La Unión, 15-agosto-1936, p. 11.

10 Así estaba Constantina, otro pueblo de la Sierra Norte de Sevilla, en el momento en el que entraron las tropas. La Unión, 12-agosto-1936. 
primeros momentos en la lucha; aunque una Falange, también, y esto fue lo que a las derechas les llamó la atención, que en la retaguardia comenzó a protagonizar marciales paradas a imagen y semejanza de las que llevaban a cabo los fascistas italianos o los nazis alemanes. En los frentes de batalla morían, como veremos dentro de poco, muchísimos falangistas, pero en la capital «las concentraciones, los desfiles, las solemnes misas al aire libre en las grandes plazas, los rituales nocturnos de antorchas eran practicados tan asiduamente en la ciudad por los uniformados de camisa azul, requerían tantos ensayos para alcanzar la perfección de la estética fascista", que los sevillanos tuvieron todo el derecho del mundo «a preguntarse qué tiempo les quedaba libre a aquellos hombres armados para combatir» ${ }^{11}$. Una duda legítima que, sin embargo, se apoyó en una percepción torcida de la realidad. Veamos por qué.

Durante la República, la Falange de José Antonio se había estructurado en la Primera y la Segunda Línea. Así, el día que el nuevo afiliado acudía a las sedes que la Falange tenía diseminadas por toda España, éste debía cumplimentar una serie de requisitos antes de que los mandos le expidieran su carné de militante: la declaración de orígenes políticos, la elección de la mensualidad que a partir de entonces abonaría, la aportación de los datos personales y, lo que ahora más nos interesa, su inclinación entre una de estas dos secciones. Inmersos en una difícil coyuntura que a la postre se traduciría en dos periodos de clandestinidad, constantes registros policiales, numerosos cierres de sus locales, así como el encarcelamiento de cientos de sus afiliados por toda España, incluido el propio José Antonio, aquella alternativa que comentamos, siempre libre y nunca sujeta a las imposiciones del mando, se convirtió en cualquier cosa menos en una elección fácil: todos los que ingresaron en la Falange supieron en todo momento qué riesgos reportaba una y qué beneficios podía depararles la otra. Siendo conscientes, por tanto, de lo que se estaban jugando, si elegían la Segunda Línea, la militancia del nuevo afiliado dentro de la Falange transcurría, por regla general, sin mayores sobresaltos, dedicándose éstos a los clásicos trabajos políticos que siempre son necesarios en una organización partidista. Ahora bien, todo cambiaba si el día del alta se optaba por la pertenencia a la Primera Línea. Ésta, a imagen y semejanza de lo que ya entonces había ocurrido con las organizaciones fascistas de Italia y Alemania, fueron las clásicas escuadras de combate formadas por individuos dispuestos a todo: a presentarse como voluntarios para vender la prensa del partido en los barrios obreros dominados por los partidos y sindicatos de izquierda, para explicarles a los anarquistas en sus propias sedes las bondades del mensaje de la Falange, tal y como hicieron los falangistas de Jerez de la Frontera en una ocasión; unas escuadras, en suma, en las que se integraron todos aquellos pistoleros y jóvenes armados que durante el período republicano habrían de protagonizar los conocidísimos enfrentamientos con la izquierda; jóvenes que llegado el 18 de julio pondrían sus vidas al servicio de los sublevados.

11 Lazo Díaz, A.: Retrato de fascismo rural en Sevilla, Sevilla, Universidad, 1998, p. 30. 
Dejando de lado el porcentaje de los que pertenecieron a una u otra sección durante la República ${ }^{12}$, lo que ahora nos interesa es seguir de cerca qué estuvo ocurriendo en aquellas milicias durante las primeras semanas de la contienda para ver, así, qué pudo haber de cierto en aquellas arremetidas de la derecha reaccionaria contra los falangistas. Para ello, lo primero será en qué situación queda la Falange tras el 18 de julio, cuestión importante para seguir de cerca las angustias de aquella extrema derecha no fascista que tanto criticaba a la Falange. Angustias, decimos bien, porque al acudir a las fuentes que han conservado el retrato de lo que estuvo ocurriendo, lo primero que llama la atención es la avalancha de afiliaciones que experimentó la Falange y sólo la Falange, y que la convirtió en sólo cuestión de meses en una organización de masas totalmente incomparable a cualquier otra de las organizaciones que se alzaron contra la República. En el sur de España, que es donde hemos completado el estudio, lo que sucedió está muy claro: en aquellos pueblos donde el partido joseantoniano aún no se había establecido, éste se constituía nada más ocuparse las poblaciones, comenzando inmediatamente la avalancha. $Y$ en los pueblos donde FE de las JONS ya estaba presente, ésta pasaba a convertirse casi de la noche a la mañana en esa organización incomparable en el número de afiliados que venimos comentando. Así, la Falange sevillana, en cuestión de muy pocos meses y cuando 1936 tocó a su fin, ya no se parecía a la organización política del periodo republicano: desde el 18 de julio y durante las semanas y meses que fueron transcurriendo hasta el final de aquel primer año de guerra, acudió a los cuarteles falangistas como mínimo el $57,1 \%$ de la militancia total que consiguió atraer el falangismo sevillano, militancia que habría de incrementarse un 13,9\% más durante los meses de 1937 que siguieron hasta el Decreto de Unificación. Es decir, antes de que FE-JONS absorbiese a todas las organizaciones sublevadas contra la República y antes también de que la Falange se hubiese convertido en el Partido Único, ésta contaba ya con más del $70 \%$ de la militancia total que llegaría a reunir ${ }^{13}$. Una avalancha que, por supuesto, no fue exclusiva de la Falange sevillana ni tampoco de la andaluza en general, sino algo común a toda España: la Jefatura Provincial de Vizcaya, por ejemplo, fue una de las que informó sobre el enorme crecimiento que en sólo tres meses los hizo pasar de los 6.500 afiliados a los 10.041 que se recogían en aquel parte ${ }^{14}$. Sigamos.

Otra pista, igualmente importante para nuestra reconstrucción de lo ocurrido, podemos hallarla en la comparación del estado en el que fueron quedando los dis-

12 Durante el periodo republicano de la Falange, los que pertenecieron a la Primera Línea fueron mayoría, tanto en los pueblos de la provincia de Sevilla, como en la capital: 65,9\% de militantes acogidos a la Primera Línea en la Falange de la capital, $68 \%$ de falangistas haciendo lo mismo en las falanges de la provincia, por un $29,7 \%$ de militantes adscritos a la Segunda Línea en la capital y otro 32\% de los que hacían lo mismo pero en las Segundas Líneas de las falanges de pueblo. Estos datos en PAREJO FERNÁNDEZ, J.A.: Las piezas perdidas...

${ }_{13}$ Los datos en PAREJo FERnÁndez, J.A.: Las piezas perdidas..., capítulo II.

14 Archivo General de la Administración (A.G.A.), Presidencia (P.), Secretaría General del Movimiento (S.G.M.), Delegación Nacional (D.N.) de Justicia y Derecho, Caja 52/02.971. 
tintos socios que se habían sublevado contra la República. Interesante porque al hacerlo, enseguida vamos entendiendo lo que estuvo pasando realmente. $Y$ es que mientras los falangistas, día tras día, se vieron sobrepasados por aquella riada de vecinos que desde el 18 de julio estuvo llamando a sus puertas, lo que vivieron por aquel entonces los carlistas de la Comunión fue totalmente diferente y opuesto. Así, si, por ejemplo, en Marchena (provincia de Sevilla) acudieron a la Falange nueve vecinos entre el 20 de julio (día de la ocupación militar) y el 31 de ese mismo mes y 153 durante el mes de agosto de 1936, en la Comunión Tradicionalista, en cambio, no acudió nadie durante ese mes y medio. $Y$ esto que pasaba en este pueblo también estaba ocurriendo por todos sitios: en Paradas, noventa y tres se afiliaron a Falange Española en el transcurso del mes de agosto por ninguno en el carlismo; en Villaverde del Río, sólo fueron 14 los que se dieron de alta en las filas de la Tradición en el mes de septiembre por 164 en la Falange; o en Lebrija, uno de los pueblos más poblados de la provincia de Sevilla, donde la Falange local en el mes de octubre ya tenía inscritos en sus ficheros a 355 nuevos falangistas por los escasos 33 lebrijanos que se dieron de alta en el Requeté15. Tal fue el éxito falangista y tal el fracaso de la Comunión Tradicionalista-Carlista en la carrera por la conquista de nuevos afiliados, que más que seguir con las cifras lo mejor es acudir al Gráfico 1 donde, a través de una comparación entre 19 falanges y requetés de pueblo, podemos ver la disparidad de la que hablamos.

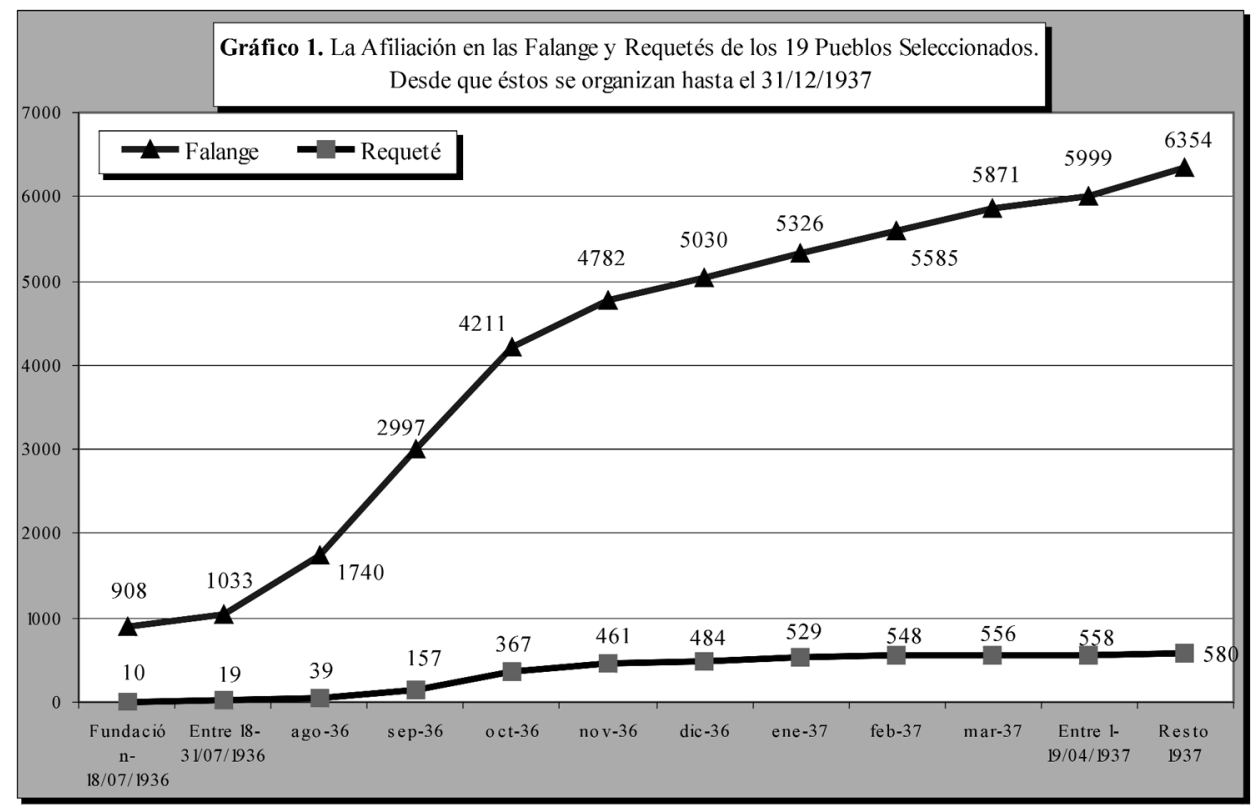

15 Parejo Fernández, J.A.: Las piezas perdidas..., capítulo II. 
Así pues, ya podemos ir intuyendo algo más: con una preponderancia política como la que estaba alcanzando la Falange en las provincias, si uno era un reaccionario era lógico que tuviese razones para preocuparse. No obstante, acudamos a un elemento más para completar nuestro retrato: la normativa que reguló el funcionamiento de las milicias falangistas.

Debemos tenerla en cuenta, entre otras cosas, porque esas normas y la organización interna de las milicias que imperaron durante los primeros tiempos del conflicto nos pueden ayudar y, por tanto, acercar a la realidad de aquellos días; unos momentos iniciales de guerra en los que la Falange, al igual que hicieran las otras organizaciones contrarias a la República, estuvo publicando en la prensa, un día sí y el otro también, numerosos artículos y consignas con el objeto de captar cuantas adhesiones les fueran posibles; unos anuncios en los que los sevillanos pudieron leer cosas como las siguientes:

Los jóvenes en plena lozanía física tienen un puesto: la primera línea de las milicias. Aquellos que por sus condiciones de edad, salud, familia, etcétera, puedan justificar moralmente su ausencia de los puestos de vanguardia, tienen también el suyo: la segunda línea. El sentido nacional de Falange nos obliga a admitirles. Es preciso evitar que se disgreguen en otras organizaciones donde se siente a España con intensidad, con hondura, pero no con nuestro estilo de pasión, no con la temperatura de abnegación y sacrificio en que han sido forjadas nuestras centurias de hierro $[\ldots]^{16}$.

Moralmente podían y debían hacer un esfuerzo, aunque nada más: en el partido nadie les obligaría a inscribirse en la Primera Línea. Por eso, si en un momento dado alguno de aquellos jóvenes, de espléndida lozanía física, decidía que su lugar no estaba en la Primera Línea por cualquier razón, no pasaba nada: en la comunidad nacional a las que aspiraban los fascistas todos tenían cabida, siempre y cuando todo el mundo hiciese suyo el objetivo de grandeza que propugnaban los jerarcas, de ahí que en los partidos totalitarios como la Falange se admitiese a todo tipo de españoles. Una integración, propia de todo fascismo, que no estuvo reñida con que aquel falangista supiese cuáles eran las ideas básicas que presidían el funcionamiento de la sección menos expuesta de la Falange: «temple de milicia, servicios propios de una milicia de reserva y espíritu tieso en los días de guerra y en los años de paz ${ }^{17}$. O lo que es lo mismo: durante los primeros tiempos del conflicto cada cual decidió el lugar en el que inscribirse.

Todo esto, sin embargo, comenzó a cambiar poco después de la Unificación, concretamente al mes siguiente, cuando la oficina de milicias de FET empezó a variar la estructura y composición de las milicias falangistas. Así, a partir de entonces y en virtud de aquella nueva normativa que comenzaron a recibir las jefaturas locales, todos los militantes que estuviesen comprendidos entre los 18 y 30 años tu-

\footnotetext{
16 Ibídem.

17 Ibídem.
} 
vieron que adscribirse obligatoriamente en la Primera Línea, salvo en las contadas ocasiones que preveía la nueva normativa ${ }^{18}$. Posteriormente, en el mes de marzo de 1938 y tras casi veinte meses de guerra, la cosa empeoró aún más cuando la Comandancia Provincial de las Milicias de FET fijó detalladamente y por escrito cuáles iban a ser a partir de entonces las ordenanzas que habrían de gobernar el normal transcurrir de las Falanges locales. Una extensa y detallada normativa de la que nosotros extractamos lo relacionado con la Primera y la Segunda Línea:

\section{INSTRUCCIONES PARA LOS JEFES DE MILICIA LOCAL DE LOS PUEBLOS DE LA PROVINCIA DE SEVILLA}

1. ${ }^{\circ}$ Milicia

a) Se considerarán incluidos en la Milicia, todos los afiliados comprendidos entre los 18 y 50 años, formando la primera línea, los de 18 a 30 años, y el resto la segunda.

b) Todos los afiliados que por su edad pertenezcan a la Milicia, dependerán militarmente y para cuantos servicios se les encomienden, de los mandos de Milicia, quedando por tanto y de acuerdo con la legislación vigente, sujetos al Código de Justicia Militar.

c) En las localidades en que las necesidades del servicio y según el número de afiliados aptos para prestarlos, no sé (sic) el total empleo de todos los comprendidos en las mencionadas edades, podrá el Jefe de Milicia, reducir el límite de edad hasta los 40 años.

d) Todos los individuos pertenecientes a la $1 .{ }^{\mathrm{a}}$ Línea, que por circunstancias especiales permanezcan en sus pueblos y no accidentalmente tienen la obligación de prestar los servicios a la Milicia Local encomendada.

e) Queda terminantemente prohibido que figuren en $2 .{ }^{a}$ Línea, los individuos comprendidos ente los 18 y 30 años, así como también que figuren en las Organizaciones Juveniles, individuos que hayan cumplido los 18 años, es decir que al lle-

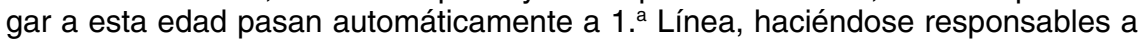
los Jefes de Milicia, del más exacto cumplimiento de esta disposición [... ${ }^{19}$.

Atrás quedaban aquellos tiempos en los que el afiliado pudo escoger su destino, el asunto ya no admitía dudas: todo el que tuviera entre 18 y 30 años pasaría a la Primera Línea y, por tanto, a estar presto, como miliciano del partido, a cumplir cualquier misión que le encomendaran sus mandos. Ahí, sin embargo, no acabó el asunto. Al mes siguiente de aquella extensa normativa, en abril de 1938, la Comandancia Provincial de la Milicia volvió a enviarles a todos los mandos locales una nueva circular, mucho menos extensa que la anterior aunque no por ello menos clara y precisa, en la que les trasladaba lo siguiente: «los de $1 .^{\text {a línea no }}$ pueden estar en la localidad si no es con documentación debidamente legaliza-

18 Salvo los que desempeñasen «servicios públicos de difícil sustitución». Archivo Municipal (A.M.) de Paradas, Leg. 463, 19-mayo-1937.

19 La normativa en A.M. de Estepa, Leg. 665, 15-marzo-1938. 
da» ${ }^{20}$. Fueron las medidas que siempre se toman en circunstancias como éstas, cuando la guerra se alarga y los ánimos bélicos del principio han desaparecido dejando lugar a los horrores propios de todo conflicto, las mismas que al poco tiempo volvieron a tomar los mandos de las milicias falangistas cuando dispusieron que la baja en la Primera Línea sólo se les iba a conceder a «los camaradas caídos»²1.

Tres pistas, por tanto, la avalancha de afiliaciones, lo exiguo de éstas en la Comunión Tradicionalista-Carlista y la evolución de la normativa interna en las milicias de FET que unidas entre sí nos permiten pasar a la siguiente fase de nuestro retrato. Dicho de otro modo, aquellas continuas campañas que, a la postre, acabarían lastrando la imagen de los falangistas en todos los ámbitos del país, tanto que incluso sus efectos han llegado hasta nuestros días, se fue fraguando en unos momentos - recordemos - en los que los afiliados de la Falange aún tuvieron en sus manos la posibilidad de elegir en qué sección de la Organización querían entrar. Significa esto que si aquella extrema derecha autoritaria y no fascista hubiera tenido razón, si el miedo a una posible muerte, si la falta de espíritu patriótico o si aquellas ansias por escapar a los peligros de la guerra hubiesen sido los motivos por los cuales tantos españoles se apuntaron a la Falange, entonces lo más lógico hubiese sido que a todos los supuestos emboscados los hubiésemos visto encuadrándose mayoritariamente en la Segunda Línea, pues ¿qué sentido tenía escapar de un peligro cuando todo el mundo sabía los riesgos que comportaba la Primera Línea? El problema, sin embargo, es que una cosa fue lo que denunciaron los miembros de la extrema derecha española, reaccionaria y totalmente opuesta al modelo totalitario de su socia la Falange, y otra muy distinta lo que ha estado esperándonos en unos archivos donde lo guardado desmiente, punto por punto, todos los argumentos que se utilizaron durante aquella campaña contra la Falange.

Fuentes, en efecto, que lejos de lo comúnmente admitido, nos muestran a una Falange en primera línea de batalla desde los primeros instantes del conflicto, de una guerra en la que sus militantes comenzaron a morir a un ritmo y en un número muy superior al que lo estuvieron haciendo sus socios de Cruzada, fuesen éstos militares, requetés o cualquier miembro de las otras unidades que durante aquel tiempo estuvieron guerreando contra la República. Tomemos, pues, como ejemplo el siguiente documento en el que se va apreciando lo que decimos:

RELACIÓN DE LOS INDIVIDUOS MUERTOS EN ACCIÓN DE GUERRA HASTA LA FECHA Y QUE HAN SIDO SOCORRIDOS SUS FAMILIARES CON LAS CANTIDADES QUE SE EXPRESAN

FALANGE ESPAÑOLA

Nombres

D. Joaquín Julio Fernández

D. Luis Mensaque Arana
Pesetas

5,000

5,000

20 A.M. de El Garrobo, Leg. 170, 8-abril-1938, «Instrucciones a los Jefes Locales de Milicia para la confección de los estados quincenales de fuerzas».

21 Ibídem. 
D. Francisco Díaz García

D. Enrique Morón Rubí

D. Carlos Shaw García

D. Manuel Fernández Paredes

5,000

D. Serafín Sastre García

5,000

D. Federico de los Santos Álvarez

5,000

D. Julio Ercilla Bustingorri

5,000

REQUETÉ

D. José Santos

10,000

JARCA DE BERENGUER

D. Ramón Pérez Álvarez

REGIMIENTO INFANTERÍA GRANADA N. ${ }^{\circ} 6$

Teniente D. Juan González Fernández

5,000

Sargento D. Jacinto García Vela

5,000

BATALLÓN ZAPADORES MINADORES N. ${ }^{\circ} 2$

Alférez de Complemento D. Agustín Rivera de Silva

5,000

Sargento de Complemento D. Manuel Olmo Sánchez Castilla

5,000

REGIMIENTO CABALLERÍA DE TAXDIRT N. ${ }^{\circ} 7$

Cabo D. Manuel Maqueda Palma

El primer mes de guerra, una relación de individuos muertos en combate en la que, ya de entrada, se aprecia una mayoría de falangistas entre los caídos. Pero una lista en la que no están todos los combatientes que perdieron la vida durante aquel mes, sino sólo los más pobres, aquéllos cuyas familias fueron socorridas con cinco pesetas. Familiares, por ejemplo, como los de Julio Ercilla Bustingorri: un falangista de primera hora, estudiante de derecho el día que se afilió al partido de José Antonio (16 de febrero de 1934), integrante desde el principio de la Primera Línea sevillana, soltero, amigo personal de Antonio García Carranza, el hermano del torero Pepe «El Algabeño» — también falangista y uno de los héroes de la Falange sevillana muerto a fines de 1936 en el frente de Jaén-y el que lo presentó en el partido, Secretario Provincial del SEU, apoderado de la Falange en las elecciones de febrero de 1936, cuando Julio Ercilla, nacido en Guernica, firmó su ingreso en la Organización lo hizo comprometiéndose con una mensualidad de dos pesetas; cuota que, como ya sabemos ${ }^{23}$, lo situaba entre los afiliados más modestos de la Falange sevillana, de ahí que a su muerte, acaecida el 17 de agosto de 1936, lo incluyeran en aquella relación donde fueron a parar los caídos más po-

22 Archivo Intermedio de la Región Militar Sur, Caja 5.364. Firmaban el documento el General Merry, el Comandante Cuesta Monereo y Eladio Goizuela, Sevilla, 23-agosto-1936.

${ }_{23}$ Para un análisis en profundidad de las cuotas abonadas por los afiliados puede acudirse a estos trabajos: PAREJo FeRnÁndeZ, J.A., La Falange en la Sierra Norte... o bien a nuestra Tesis Doctoral ya citada. También puede consultarse el tema aunque de manera más resumida en LAZO DíAZ, A. y PAREJO FERNÁNDEZ, J.A.: «La militancia falangista en el suroeste español. Sevilla», en Ayer n. ${ }^{\circ} 52$ (2003), pp. 237253. 
bres $^{24}$. Un falangista y unos falangistas, por tanto, que, frente a la leyenda de los emboscados, nos muestran el verdadero papel que estuvo desempeñando la Falange en aquella guerra que por aquel entonces sólo estaba comenzando.

En 1940, la Universidad de Sevilla publicó el Libro Áureo, donde aparecía la lista de todos los alumnos, profesores y antiguos estudiantes de la Hispalense muertos durante la guerra civil. En él, aparte de los datos biográficos del alumno fallecido, también se indicaban los orígenes políticos de cada uno, resultando que, al comparar unos con otros, las bajas de los estudiantes falangistas fueron muy superiores a las de aquéllos que habían pertenecido al Requeté o a las Milicias Nacionales. Y es que basta con acudir a libros como el que acabamos de citar o a los documentos guardados en los archivos para comprobar inmediatamente cómo ese emboscamiento del que tanto se hablaba por todos sitios no existió como fenómeno generalizado. Unos archivos, en efecto, que han estado guardando entre sus fondos el mejor y único instrumento para averiguar definitivamente si aquella extrema derecha tuvo razón cuando mencionó una y otra vez el asunto de los emboscados: las fichas, los expedientes y los carnés de los propios falangistas. Así, si, como decíamos antes, el miedo hubiese sido lo único que estuvo detrás de aquellas afiliaciones masivas a la Falange, entonces nosotros, nada más repasar aquellos expedientes y sumar los datos en ellos reflejados, deberíamos haber obtenido una imagen idéntica a la transmitida en aquella leyenda por todo el mundo conocida. Pues, si hay miedo lo más lógico habría sido que la Segunda Línea, a la que todo el mundo pudo acudir libremente durante el primer año y medio de guerra ${ }^{25}$, hubiese estado repleta de camaradas miedosos de ir al frente y miedosos, también, por la posibilidad más que real de perder sus vidas en la lucha contra la República. Sin embargo, contando y sumando los datos consignados en los miles de expedientes hallados en los archivos municipales, resulta que la imagen obtenida no se parece en nada a la que hasta ahora nos ha ocupado. Fundamentalmente porque si algo prueban los datos de archivo es que en las filas de la Falange sevillana predominaron los falangistas encuadrados en la Primera Línea: un $50,9 \%$ frente a un $49,1 \%$ en la Segunda Línea. A simple vista nuestro argumento parece débil: no hay diferencias entre ambas secciones. Esto, no obstante, se explica por una razón que ya conocemos: la normativa interna sobre milicias de FET. En efecto, como podrá apreciarse en el Gráfico 2, la Segunda Línea estaba repleta de camaradas casados $(72,7 \%)$ y, por tanto, con unas responsabilidades familiares que, sin duda, los hacían poco propicios para la Primera Línea. Aparte, tampoco debemos perder de vista cómo un $78,3 \%$ de los que integraron la Segunda Línea superaban la barrera de los treinta años, que fue, como sabemos, el límite que en 1938 establecieron los mandos, sin contar — también-que estos datos corresponden a

${ }^{24}$ La semblanza de Julio Ercilla Bustingorri, arquetipo falangista, en el Archivo de la Falange de Sevilla (Privado), Legajo A-G, carpeta E-F, ficha $n .{ }^{\circ} 161$.

${ }_{25}$ Período, recordemos, en el que la Falange adquirió la gran mayoría de los militantes. 
la reestructuración que se hizo en los ficheros a raíz de aquellas circulares que comentábamos.

A la Primera Línea, por tanto, fueron a parar todos los que estaban en perfectas condiciones de revista: los que gustaron del espíritu aventurero, de la violencia, del arrojo o del desenfreno bélico, así como los que pudiéndose quedar en la Segunda Línea, bien por cuestiones familiares o por simple cuestión de edad, se empeñaron en guerrear con las Banderas de Falange.

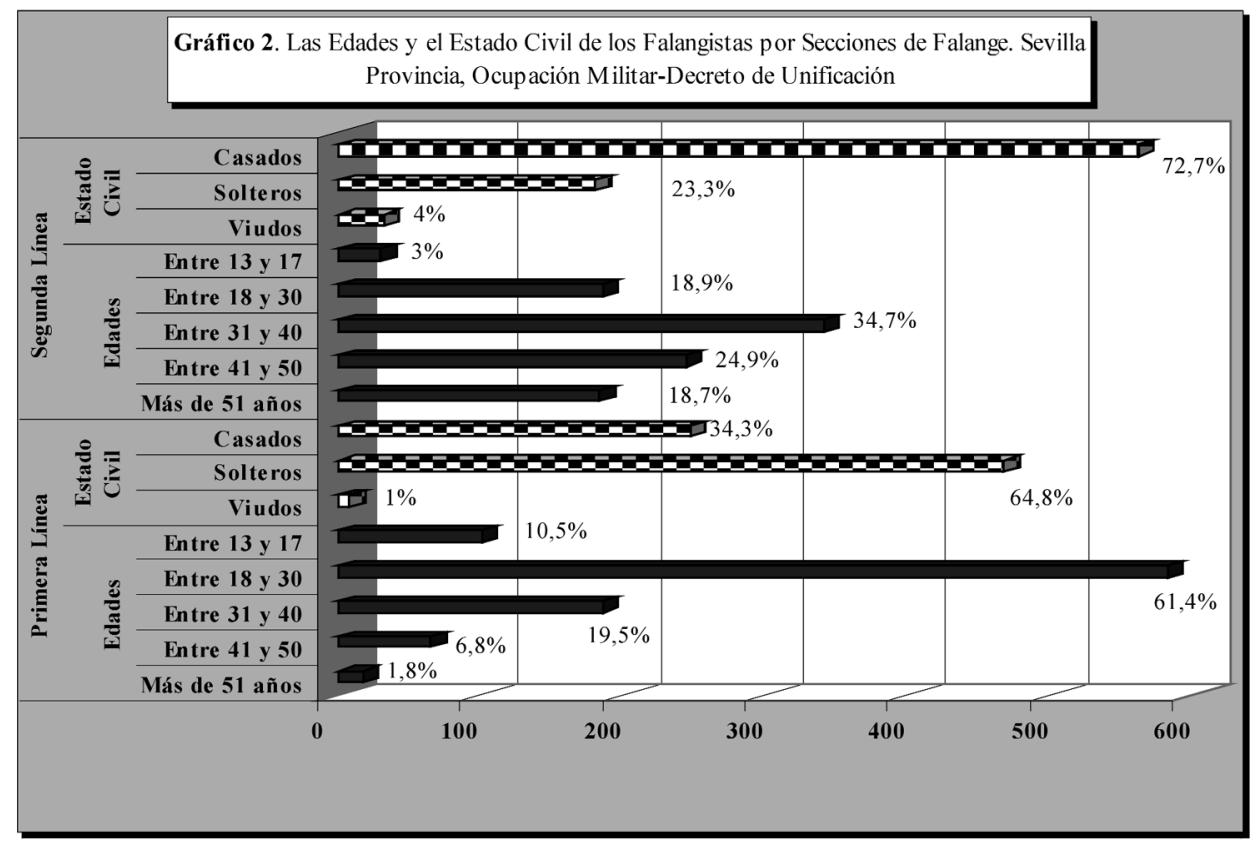

De ahí que en éstas nos encontrásemos a una mayoría de solteros (el 64,8\%) y jóvenes combatientes: el $61,4 \%$ tenía entre dieciocho y treinta años. Aunque hay más. Según los informes guardados en los archivos, aquella inclinación de las bases hacia el riesgo no fue una cosa privativa de la Falange sevillana, sino algo común y extensible a todas las falanges del territorio nacional. Los datos hallados en el Archivo General de la Administración de Alcalá de Henares muestran cómo la distribución entre la Primera y la Segunda Línea de la Falange onubense fue prácticamente la misma que la vista en el caso sevillano: un $51,3 \%$ de los falangistas estuvieron encuadrados en la Primera Línea por un 48,7\% en la Segunda ${ }^{26}$. O el caso de la Falange de Tánger, donde al hacer el recuento resultó que también allí la mayoría de los efectivos pertenecieron a la Primera Línea: 147 falangistas españoles y 228 nacionalsindicalistas de origen marroquí, es decir, el $71,4 \%$ del to-

26 A.G.A., P., S.G.M., Caja 51/18.946, Nomenclátor de la Provincia de Huelva, 23-abril-1937. Aquí también se recogen las cifras de toda la Falange onubense. A ese 51,3\% pertenecían 7.172 falangistas y al $48,7 \%$ de la Segunda Línea un total de 6.814 camaradas. 
tal de la militancia no tuvo ningún reparo a la hora de encuadrarse en la sección más expuesta de la Organización ${ }^{27}$. Una realidad que todavía se percibe mejor en la Jefatura Provincial de Tenerife. En las islas, al igual que hicieron los mandos de la colonia española, los de Huelva o los de Sevilla se contabilizaron los distintos sectores de la Falange tinerfeña, aunque aquí fueron un poco más detallados, con lo que hoy no sólo conocemos cómo la inmensa mayoría de aquellos falangistas canarios pertenecieron a la Primera Línea $(74,8 \%)$, sino cómo casi todos estuvieron luchando, además, en la península: de los 2.277 militantes de Primera Línea en el momento del cómputo, 1.828 estaban luchando ya en los frente de batalla ${ }^{28}$. Ahora bien, como una cosa es la frialdad de los datos numéricos y otra bien distinta el ánimo con el que afrontaron los militantes su pertenencia a la Primera Línea, lo mejor es que nos acerquemos a una de las tantas correrías bélicas que protagonizaron los falangistas durante la guerra para ver de cerca cómo lucharon aquellos falangistas contra la República.

El 19 de julio, a las once de la mañana, nada más recibir la orden de presentarse cuanto antes en el Cuartel Soria de la capital, los falangistas de Estepa (un pueblo a 100 kilómetros de Sevilla) partieron hacia la acción sin dudarlo. Los que se fueron hacia Sevilla aquella jornada eran cualquier cosa menos unos militantes acobardados. Así, pese a que tuvieron la posibilidad de dar marcha atrás en el último momento, todos se prepararon para el viaje. A las dos y media de aquel día, la hora fijada para la partida, uno de los tres automóviles fue tiroteado «por los comunistas al tiempo de arrancar, alcanzando uno de los disparos al camarada Manuel Galván Prieto, produciéndole tan graves heridas que a consecuencia de ellas falleció el día 27 de agosto último". Con un coche inutilizado, con un camarada herido de muerte y obligados a separarse siguieron, sin embargo, con el plan previsto. El primero de los dos coches tomó el camino de Osuna. Como les cogía de paso, a la altura de aquel bonito pueblo hicieron la primera parada para descansar, aunque bien mirado poco descansaron: nada más ser vistos fueron recibidos a tiros, teniendo entonces que alterar el itinerario preestablecido y tomar la carretera de Écija. No obstante y a pesar de aquel rodeo, tampoco les fue posible llegar a Sevilla por aquel camino ya que, si bien los sublevados ya controlaban Écija, Carmona, paso obligado para entrar en la capital, aún no había caído; con lo que después de haberse arriesgado por las carreteras de La Campiña comprobaron que no había manera de cumplir con el plan previsto. Incomunicados como estaban, no les quedó otra que ponerse provisionalmente a las órdenes de los militares sublevados de Écija. Y así estuvieron hasta el 22 de julio cuando, despejado el camino, conquistada Carmona, tuvieron vía libre para plantarse en Sevilla. Mientras pasaba esto con el primer grupo, los otros falangistas que iban en el segundo automóvil también experimentaron peripecias de todo tipo. Tantas que al final sólo pudieron llegar hasta Arahal, un pueblo a casi cincuenta kilómetros de la capital en

27 Ibídem. En la 2. ${ }^{a}$ Línea había 150 militantes, el 28,6\% del total

28 Ibídem, informe del 15-abril-1937. En la Segunda Línea estaban 766 falangistas (25,2\% del total). 
Donde cayeron en poder de los rojos, pero valiéndose de astucia consiguieron su libertad con condición de que tenían que regresar a Estepa, cuyo regreso iniciaron y al llegar a Osuna fueron de nuevo detenidos y encarcelados hasta que el comandante Militar Capitán Hinojosa, con fuerza de la Guardia Civil a sus órdenes se hizo cargo de la plaza y los puso en libertad, dándoles armas y poniéndoles a sus órdenes, donde estuvieron en continua guardia en defensa de aquella población, hasta que pasó la columna del comandante Castejón e incorporados a ella llegaron a Estepa al mismo tiempo que los que venían de Sevilla ${ }^{29}$.

Habían pasado nueve días de arriesgadas travesías; habían sufrido tiroteos que casi les costaron la vida; fueron encarcelados y habían participado en una encarnizada resistencia (los que consiguieron llegar a la capital se enrolaron en la columna el 28 de julio); ¿qué más se podía esperar de ellos? Pues eso, que nada más tuvieran otra oportunidad se enrolasen en una nueva escuadra y marchasen a la guerra sin pensarlo. $Y$ eso es lo que hicieron. Después de todos los peligros narrados, nuevamente pudo vérseles reunidos participando en una nueva aventura: la toma de su pueblo, Estepa.

Esta historia de los falangistas de Estepa, volvemos a insistir, sólo fue una gota en medio de un océano en el que cientos y cientos de falangistas sevillanos perdieron sus vidas luchando contra la República. Joseantonianos como aquel joven falangista de Cazalla, menor de edad, que tantas veces se les escapó a sus padres para irse al frente; historias como la de multitud de jovenzuelos, los cuales, a pesar de sus insistencias, se quedaron en sus pueblos porque no tenían la edad mínima para ir al frente; casos como el de aquel otro de La Campana empeñado en reincorporarse al frente cuando, según los médicos, aún no se había repuesto de su enfermedad; historias, en definitiva, de tantos y tantos falangistas que con su arrojo y violencia propias de todo fascismo contribuyeron al derrocamiento de la Segunda República ${ }^{30}$. Así, mientras los llamaban emboscados, las trayectorias personales de estos falangistas demostraron cuán equivocados estuvieron todos los que así los calificaron. En efecto, a tanto ascendieron las bajas, tantos fueron los muertos en las diferentes banderas de la Falange que en agosto de 1937, al año escaso de iniciada la guerra, la Jefatura Provincial de Milicias no tuvo más remedio que enviar a todas las agrupaciones de la provincia la siguiente circular:

La escasez de personal en las Banderas de Falange que se encuentran en los frentes de combate y muy particularmente el de la Segunda Bandera del frente de Madrid que debido a su heroico comportamiento ha visto reducidos de tal modo sus efectivos que de no enviarle elementos, nos veríamos en el caso de disolverla perdiendo por tanto Falange de Andalucía el honor de que para ella representa el contar en el Ejército de la Primera Región con una Bandera que tan alto ha sabido poner nuestro nombre $[\ldots]^{31}$.

29 A.M. de Estepa, Libro de los hechos más sobresalientes realizados por las Milicias de esta Falange.

30 Éstas y otras tantas en PAREJo FERnÁNDEZ, J.A.: Las piezas perdidas..., capítulo II.

31 A.M. de El Garrobo, Leg. 170, circular de 11-agosto-1937. 
Pedían reemplazos porque los camaradas seguían muriendo a un ritmo tal que la continuidad de aquellas unidades corría serio peligro. $Y$, sin embargo, a pesar de ser un pilar fundamental en la estrategia de los sublevados desde el principio, los falangistas continuaron cargando con aquel estigma que los hizo ser, a ojos de sus propios socios, unos cobardes despreciables. Una campaña falsa de la que se derivaron con el paso del tiempo una serie de consecuencias que acabarían lastrando el futuro de la Falange. En efecto, cuando iniciada la Segunda Guerra Mundial comenzase el reclutamiento de la División Azul, la primera hornada de voluntarios tuvo una mayoría de falangistas entre sus filas, cuyas enormes bajas en el Frente del Este volvieron a manifestar lo que ya habían demostrado durante la Guerra Civil. A ella acudieron miles y miles de afiliados de toda España, a ella también destacadísimos dirigentes de FET como Dionisio Ridruejo o el sevillano Pedro Gamero del Castillo, los cuales durante la contienda española fueron tildados de emboscados por haberse quedado en la retaguardia construyendo un partido totalitario que al final no llegó a ser más que un apoyo coreográfico del régimen franquista. Por eso, las protestas falangistas, incluso callejeras, por toda España contra el hambre, las denuncias contra la corrupción de las autoridades ${ }^{32}$ sólo fueron fuegos de artificio. En 1941, cuando el desprestigio de la Falange ya era más que evidente, un lúcido y desesperado jerarca granadino no pudo dejar de reconocer cómo la política de abastos se estaba traduciendo en un hambre general y, lo que era peor, en una corriente de animadversión muy extendida contra la Falange. Y es que, pedía aquel mando, «un mejoramiento, por pequeño que sea en materia de abastos, un aclarar que la Falange no es culpable de las deficiencias de tal organización, y un darle mayor influencia en los medios oficiales, podrían robustecer el prestigio del Partido» ${ }^{33}$. Se equivocaba. En la época dorada de los fascismos, cuando Alemania seguía asombrando al mundo con sus conquistas militares, el fascismo español había perdido el apoyo popular debido, en parte ${ }^{34}$, a aquella constante campaña que empezara con el comienzo mismo de la Guerra Civil y que en aquel momento estaba mostrando su cara más cruda. En 1938, adelantándose a lo que pasaría, Bahamonde escribió lo siguiente: «Hoy Falange no es nada ni cuenta para nada» ${ }^{35}$. Tenía razón.

${ }^{32}$ En un trabajo nuestro hemos abordado esto: PAREJO FERNÁnDEZ, J.A.: «Un sermón antifalangista en los años del hambre», en Farua n. 8 (2005), pp. 143-161.

${ }_{33}$ A.G.A., P., S.G.M., D.N. de Provincias, Caja 72, Jefatura Provincial de Granada, Parte Mensual de febrero de 1941.

${ }^{34}$ Sólo en parte porque la Falange también fue acusada de haberse convertido en un paraguas protector en el que la izquierda aterrada se había refugiado para evitar los pelotones de fusilamiento. Una visión de conjunto de esto que escapa al ámbito de este artículo en nuestra Tesis Doctoral Las piezas perdidas de...

${ }^{35}$ Bahamonde y Sánchez de Castro, A.: Un año con Queipo..., p. 62. 